Article

\title{
The Easier the Better: How Processing Fluency Influences Self-Efficacy and Behavioral Intention in Pro-Social Campaign Advertising
}

\author{
Hee Jin Kim ${ }^{1}$ and Jung Min Jang ${ }^{2, *}$ \\ 1 College of Business, Gachon University, Seongnam-si 13120, Gyeonggi-do, Korea; heejinkim@gachon.ac.kr \\ 2 Management and Marketing, Bang College of Business, KIMEP University, Almaty 050010, Kazakhstan \\ * Correspondence: jmjang@kimep.kz; Tel.: +7-727-270-4440 (ext. 2056)
}

Received: 31 October 2018; Accepted: 11 December 2018; Published: 14 December 2018

check for updates

\begin{abstract}
This study examines how processing fluency influences people's behavioral intention to perform a pro-social behavior. In particular, we predict that high processing fluency enhances self-efficacy perception which, in turn, increases behavioral intention to participate in a pro-social campaign. Study 1 tested the proposed effect in the context of a pro-environmental campaign. Results showed that individual's subjective feeling of processing fluency affects the degree of self-efficacy and intention to engage in recycling behavior. Study 2 replicated study 1 in the context of organ donation. In addition, we manipulated the degree of conceptual fluency by differently pairing message framing (gain vs. loss) and background color (blue vs. red). As predicted, participants exposed to campaign advertising with conceptually matching framing-color pairs (blue-gain framing and red-loss framing) expressed a greater level of self-efficacy than those who were exposed to mismatched pairs. In addition, self-efficacy mediated the influence of the color-framing match on the intention to donate organs. Our research contributes to the existing literature by identifying critical drivers that promote actions toward pro-social campaigns. It also provides useful guidelines for marketers who design and implement pro-social campaign communications.
\end{abstract}

Keywords: processing fluency; self-efficacy; pro-social campaign advertising; social sustainability

\section{Introduction}

In recent years, public campaigns attempting to change individuals' behaviors to lead to improved social well-being and a more sustainable society have received increasing attention from researchers, practitioners, and policymakers. A unique challenge in designing such campaigns in comparison to other marketing programs stems from the gap between attitude and behavior that reflects how belief and attitude toward an issue are not translated into actions [1]. For instance, 91\% of plastic waste is not recycled [2]. Similarly, Bamberg and Moser's [3] meta-analysis of 57 studies suggests that pro-environmental intentions explain only $27 \%$ of the behavior. A similar phenomenon is often found in other pro-social domains such as organ donation. A survey shows that $95 \%$ of the U.S. population supports the idea of organ donation, but only $54 \%$ have identified themselves as organ donors. In this study, we attempt to understand the critical drivers that promote responses and actions toward prosocial campaigns. One source of the discrepancy between the level of concern and action is assumed to be the altruistic nature of these behaviors, which often have costs for individuals (e.g., inconvenience, risk, paying a higher price) to benefit unknown others or future generations [3-5]. Therefore, even if one is convinced of the desirability of a particular behavior, other self-oriented situational factors may hinder one's actions. A popular concept used in psychology and marketing to explain the gap between attitudes and behaviors is self-efficacy, defined as an individuals' expectation of their ability to achieve 
the desired outcome [6,7]. Drawing from social cognitive theory [8,9], our study uses self-efficacy as an essential construct that conceptualizes individuals' own belief about their ability to perform a particular behavior. Evidence that supports the focal role of self-efficacy in predicting behavioral intention has been documented through many studies in various domains [10-13]. Extending this line of research, we attempt to find a way to enhance people's self-efficacy judgment and likelihood to engage in pro-social behaviors through changes in the contextual factors in social marketing communication. In particular, based on fluency theory [14], we propose that when information is presented in a manner that is easy (vs. difficult) to process, people are likely to feel that they are competent to perform the needed action and thus more likely to engage in pro-social behaviors like conservation and organ donation.

We conducted two studies in which we examined the metacognitive influence of processing fluency on behavioral intention for recycling and organ donation campaigns. By doing so, we attempt to generalize our findings by replicating them in the contexts of behaviors that involve different levels of self-efficacy concerns. Specifically, demonstrating the proposed effect on a daily behavior that involves a low level of ability concerns (recycling) as well as infrequent decisions that involve a relatively higher level of self-efficacy (organ donation) may enhance the robustness of our findings. In addition, we believe that the current findings can apply to a broad range of behaviors with pro-social aspects and benefits practitioners in various non-profit organizations, highlighting the importance of ease of processing facilitated by contextual factors (e.g., color, presentation, pictures, and font). Moreover, some recent research defines sustainable behavior as the set of actions aimed at protecting both natural and social resources, including actions related to conservation of human resources (e.g., people's wellbeing and survival) [15]. Applying this definition to the current research, we attempt to validate our proposition in both the recycling and organ donation contexts and contribute to social as well as environmental sustainability. In study 1 , we show how an individual's subjective feeling of fluency toward advertising that promotes pro-environmental behavior influences self-efficacy and behavioral intention. In study 2, we manipulate the levels of fluency through the color-content match in an advertisement about organ donation and replicate the proposed effect.

\section{Self-Efficacy in Pro-Social Behavior}

Self-efficacy refers to an individual's own belief that he or she can successfully organize and execute the behaviors needed to produce a desired outcome $[8,11,16]$. A higher level of self-efficacy indicates greater perceived control and capabilities even over difficult tasks. Prior research suggests that individuals with high self-efficacy perceptions are more likely to focus their attention on the task [17], whereas individuals who doubt their capacity and achievement are likely to lose interest in the task [16]. In addition, when people feel confident in carrying out certain behaviors, they experience satisfaction from their judgments of self-competence, which promotes engagement in new actions and behaviors [18]. Further, the individual's perceived ability leads him or her to invest persistent effort into the task, effectively allocate resources, and seek for better solutions that often result in better actual performances and outcomes [19,20].

Most early findings of the strong influences of self-efficacy on judgment and behavior came in the contexts of research on health, education and organizational development. Recently, however, the concept has emerged as a critical factor in predicting pro-social behaviors. A sizable body of research has reported that high levels of self-judgment on efficaciousness facilitate conservation behaviors including recycling [21,22], electricity conservation [23], and participation in environmental causes [24]. A sense of self-efficacy also correlates with the intention to donate money [25], blood [26,27], and organs [28-30].

It is notable that the nature of decisions to engage in such pro-social behaviors differs from that of decisions in other domains. General decisions typically involve assessments of benefits and costs that are relevant to the individual's self. In contrast, pro-social behaviors are unlikely to bring direct personal gains and likely to cost individuals' resources [31]. However, individuals may anticipate psychological rewards when engaging in a good deed such as experiencing happiness, avoiding guilt, 
or enhancing self-image. Moreover, they are likely to make a positive decision if the potential rewards outweigh the sacrifice [32].

Some researchers argue that self-efficacy contributes to making pro-social behavior intrinsically rewarding. Because people experience satisfaction from feeling competent in acting for others' benefit, spending time and effort in executing these behaviors is perceived as less of a sacrifice and cost [21]. Hence, high self-efficacy is likely to evoke personal interest in the altruistic behavior itself and increase the intention to perform the behaviors. In addition, although pro-social acts are performed with the altruistic intention of promoting the welfare of other individuals and groups, people will neither engage in the action nor persist in those behaviors if they do not feel capable of doing so. In light of the findings from the above research, we propose the following hypothesis:

Hypothesis 1 (H1). Self-efficacy has a positive effect on behavioral intention toward pro-social behavior.

\section{Processing Fluency, Self-Efficacy, and Behavioral Intention}

In the current research, we propose a feeling of easiness in processing the stimuli (processing fluency) as one source of self-efficacy. People may process any stimulus with different degrees of fluency [15]. Researchers have identified two distinct types of processing fluency: perceptual and conceptual [33]. Perceptual fluency is obtained by influencing the easiness of recognizing the stimulus. Familiarity from prior exposure or the physical features of target stimuli such as symmetry play vital roles in increasing perceptual fluency [34]. Conceptual fluency is related with the ease of understanding the meaning of the stimulus $[33,35,36]$. Much research has showed that conceptual fluency can be enhanced by presenting conceptually related constructs together [37]. For instance, people more fluently process the target stimulus (e.g., a picture of a lock) when it is presented in an associated context (e.g., after showing the word "lock") than not (e.g., after showing the word "key") [36].

Numerous studies have demonstrated that experiencing fluent processing not only affects the actual speed and accuracy of information processing but also influences individuals' responses to the target stimulus [33,38]. Liking [39,40], aesthetic evaluation [34], and perceived importance [36,41] are positively influenced by the level of processing easiness. Prior research ascribed this phenomenon to changes in affective reactions. That is, easy processing of a stimulus elicits a positive affective state that people misattribute to the stimulus information itself rather than the processing easiness [36].

Applying the fluency effect in a pro-social context, we propose that fluent processing experiences can serve as a source of efficacy belief. According to the previous literature, people's beliefs concerning their efficacy can be created and strengthened by four forms of influence: mastery experiences, vicarious experiences, social persuasion, and affective states [16]. Central to our research, emotional states are used as the information to judge one's own capabilities. For instance, people perceive feelings of stress and tension as signs of vulnerability to poor performance. In a similar vein, we propose that people are likely to use the positive emotions aroused from fluent processing as information in forming their own perception of competence.

While there is limited evidence that associates fluency and self-efficacy in the pro-social literature (we are aware of only one study [42] that investigated this association), the relationship between metacognitive experiences and the level of confidence in one's ability has been widely studied in educational psychology. For instance, students predicted their performance on an upcoming test better when the information was presented in a larger font size [43] or easier-to-read style [44]. Furthermore, students judged that foreign language words would be easier to memorize when they were paired with pictures explaining their meaning than when they were paired with an English translation [45]. More relevant to the current research, previous research showed that when the advertising message for a recycling campaign was presented in a frame that fits with the readers' mindset, they found it easy to process the information and to engage in the behavior, which eventually led to a higher likelihood to engage in the recycling behavior [42]. 
Similarly, we predict that people may have a higher level of confidence in executing the actions needed for the desired outcome when the information presented in an advertisement promoting pro-social behavior is easier to process. In addition, the enhanced level of confidence or self-efficacy evoked by the processing fluency will increase the intention to engage in the behavior. Hence, we hypothesize as follows:

Hypothesis 2 (H2). Fluency has a positive effect on perceived self-efficacy toward the pro-social behavior.

Hypothesis 3 (H3). Self-efficacy mediates the influence of fluency on behavioral intention toward the pro-social campaign.

\section{Study 1}

The purpose of study 1 was to test the proposed hypotheses. Based on previous logical flow, we examined our theorem that the subjective feeling of fluency in processing the pro-social campaign advertising will enhance the level of self-efficacy, which in turn increases intention to engage in an environmental protection campaign.

\subsection{Participants and Procedure}

Participants and design: A total of 54 undergraduate students (57.4\% female) in Korea were recruited to complete an online survey using Qualtrics survey software. Participants' ages ranged from 19 to 26 years $\left(M_{\mathrm{age}}=21.5\right.$ years, $S D=1.84$ years). Participants participated voluntarily and filled out the survey for a small amount of extra course credit. The survey required less than $3 \mathrm{~min}$ to complete.

Materials and procedure: Participants first reviewed a simplified version of an actual conservation campaign advertisement that has been used nationwide to reduce the use of disposable paper cups. Specifically, the message and picture of a paper cup are presented together in the print advertisement, and the message was printed in white letters with a green background. In this stimulus, we tried to provide the most typical campaign advertisement to the participants. Then, they responded to several questions about their thoughts or feeling reactions when looking at the campaign advertising. Participants were asked to indicate behavioral intention with three items ranked on a seven-point scale $(1=$ strongly disagree, $7=$ strongly agree; Cronbach's $\alpha=0.914)[42,46]$. Participants' self-efficacy was measured using four items on a seven-point scale $(1=$ strongly disagree, $7=$ strongly agree; Cronbach's $\alpha=0.891)$ [42]. Fluency was measured with four items on a seven-point scale ( $1=$ strongly disagree, $7=$ strongly agree; Cronbach's $\alpha=0.846)$ [47,48]. We also included involvement toward pro-environmental behavior as a control variable with four items on a seven-point scale $(1=$ strongly disagree, 7 = strongly agree; Cronbach's $\alpha=0.764$ ) [49] (see Appendix A). Lastly, participants provided general demographic information including gender and age. Upon completing the measures, the participants were debriefed and thanked.

\subsection{Results}

Control variable: The predictor variable was fluency toward the advertising or advertising campaign. The dependent variable was the behavioral intention, that is, how much do they want to join the program. The potential mediator is self-efficacy, in other words, participants' perception that reducing their use of disposable cups will have a positive outcome on the environment. Before performing the analyses to test the hypotheses, we conducted correlation analysis to explore the relationships among the main variables and involvement as a control variable (see Table 1). The results of correlation analysis revealed that fluency and involvement toward environmental protection behavior are not significantly related. Therefore, we can conclude that each variable independently contributed to the expected outcome. 
Table 1. Descriptive statistics and intercorrelations among fluency, self-efficacy, behavioral intention, and a control variable.

\begin{tabular}{ccccccc}
\hline & Mean & SD & $\mathbf{1}$ & $\mathbf{2}$ & $\mathbf{3}$ & $\mathbf{4}$ \\
\hline 1. Fluency & 4.36 & 0.99 & - & & & \\
2. Self-Efficacy & 4.38 & 1.45 & $0.486^{* *}$ & - & & \\
3. Behavioral & 4.59 & 1.05 & $0.399^{* *}$ & $0.778^{* *}$ & - & \\
Intention & 3.46 & 1.49 & 0.245 & $484^{* *}$ & $475^{* *}$ & - \\
4. Involvement & SD: standard deviation; $p<0.10 ; * * p<0.01$. &
\end{tabular}

Hypothesis testing: $\mathrm{H} 1$ addresses how different levels of fluency toward the advertising campaign to encourage pro-social behavior impact self-efficacy. $\mathrm{H} 2$ addresses whether perceived self-efficacy of participants influences behavioral intention toward the pro-social campaign or not. Given the continuous nature of the variables, we conducted regression analysis to test the hypotheses using the perception of self-efficacy toward participation in environmental protection resulting from the campaign as the dependent variable, and fluency and the control variable as the predictors. The results showed that the control variable (involvement with environmental protection) was a significant predictor; as they have a stronger general tendency, participants perceived greater self-efficacy $(\beta=0.53$, $t=3.41, p=0.001)$. More importantly, as expected, fluency significantly influenced self-efficacy; participants perceived greater self-efficacy as their fluency increased ( $\beta=0.58, t=3.44, p=0.001)$. Thus, H1 was supported.

We conducted another regression to test the hypotheses using behavioral intention toward the environmental protection activity as the dependent variable and self-efficacy and the control variable as the predictors. The analysis revealed that involvement was not the significant predictor for explaining the behavioral intention ( $\beta=0.18, t=1.28, p=0.206$ ). Self-efficacy, however, significantly influenced behavioral intention $(\beta=0.72, t=6.34, p<0.001)$. Thus, $\mathrm{H} 2$ was supported. Consistent with previous literature, these results provide evidence that self-efficacy is a powerful predictor of intention to engage in pro-social behavior.

$\mathrm{H} 3$ predicted that the increase in self-efficacy would mediate the influence of fluency on behavioral intention. A bootstrapped mediation analysis was used to test the model (model 4; [50]). The mediation effect of self-efficacy (indirect effect $=0.416,95 \% \mathrm{CI}=(0.14,0.74)$ ) was significant, whereas the direct effect of fluency on behavioral intention was not significant $(\beta=0.04, t=0.25, p=0.804)$. Therefore, the observed effect was fully mediated by self-efficacy [51]. Thus, H3 was supported (see Table A3 in Appendix B).

\subsection{Discussion}

We conducted Study 1 to test our hypotheses in a natural setting and used a survey to assess whether individuals' fluency may be one of the causes of intention to engage in pro-social behaviors. In accordance with our hypothesis, we find that the more consumers perceived the environmental information as fluent for information processing, the greater their perceived self-efficacy. Participants who perceived greater self-efficacy were more likely to engage in the pro-social behavior. To provide rigorous evidence, we propose that manipulating fluency using context factors in the communication also will show a significantly similar impact on socially desirable behavior. Thus, we provide relevant literature on how to manipulate processing fluency in the next section and develop hypotheses with further details.

\section{The Influence of Manipulated Fluency: Match between Color and Framing as a Source of Fluency}

Recent studies have shown that a match between the color and the message can increase processing fluency [52,53]. Because colors have associated meanings [54-56], whether those meanings fit with the contents of information can differentiate peoples' subjective feeling of processing easiness. The colors 
that are of interest for the current study are red and blue. Red typically carries negative meanings such as danger or mistake (e.g., warning signals and traffic lights [54]), while blue is associated with positive meanings like competence and calm [57]. Prior research suggests that these meanings evoke different motivations: red primarily induces an avoidance motivation to negative consequences and blue elicits an approach motivation to positive outcomes [58]. Hence, a red color is likely to facilitate fluent processing when paired with negative contents, whereas a blue color produces conceptual fit with a message describing positive aspects [58].

Pro-social marketing campaigns can be framed in two ways. One is to describe the positive consequence of engaging in the behavior (gain framing), and the other is to depict the negative consequences if it is not performed (loss framing) [59]. Drawing on the above research on the meanings of colors, we assume that loss-framed messages can be more fluently processed with the color red and gain-framed messages can be more fluently processed with the color blue than vice versa. For instance, a message promoting recycling behavior can be processed more easily with the color red when it highlights threats to nature if one does not recycle and with the color blue when the ad highlights the expected benefit to nature by undertaking the behavior.

Hypothesis 4 (H4). Color will moderate the relationship between message framing and self-efficacy toward an organ donation campaign.

Hypothesis 4a (H4a). Consumers will show greater self-efficacy with the loss framing condition than with the gain framing when the primary color of advertisement is red.

Hypothesis $4 \mathbf{b}(\mathbf{H} 4 \mathbf{b})$. Consumers will show greater self-efficacy with the gain framing condition than with the loss framing when the primary color of advertisement is blue.

Hypothesis 5 (H5). Color will moderate the relationship between message framing and behavioral intention to join an organ donation campaign.

Hypothesis 5a (H5a). Consumers will show greater behavioral intention with the loss framing condition than with the gain framing when the primary color of advertisement is red.

Hypothesis $\mathbf{5 b}(\mathbf{H} 5 \mathbf{b})$. Consumers will show greater behavioral intention with the gain framing condition than with the loss framing when the primary color of advertisement is blue.

Hypothesis 6 (H6). Self-efficacy mediates the effects of the two-way interaction between primary color and framing on behavioral intention toward the pro-social campaign.

Study 2 will provide additional support for our hypotheses in an experimental context in which we manipulate fluency by using a match or mismatch between color and message framing.

\section{Study 2}

We conducted Study 2 to extend and replicate the results of Study 1 in a controlled experimental setting using a different framing and primary color of the advertisement. Researchers have shown that a critical source of processing fluency can be a conceptual match between the nature of message contents and visual information $[14,60,61]$. In our context, compatibility between color and message framing (red-loss frame vs. blue-gain frame) makes the message easy to understand due to the positive metacognitive experience [62]. Accordingly, we propose that combining red (blue) color with a loss (gain) frame will enhance self-efficacy toward the pro-social behavior (i.e., organ donation in this study) and result in greater behavioral intention to join an organ donation program. Consequently, we conceptually replicated the results from Study 1 in a different context. Because we used environmental protection behavior as the pro-social behavior in Study 1, it could be questioned whether using different 
types of pro-social behavior would show similar results or not. To answer this question in Study 2, we employed organ donation as the pro-social behavior in the experiment. Generally, environmental protection behavior and organ donation are considered important sustainable behaviors. At the same time, organ donation has a different and unique feature from environmental protection behavior in that it requires that people share their resources. Consistent results for Study 1 and 2 would contribute to strengthening the generalizability of our theorem in various types of pro-social behavior. Moreover, to make the results more widely generalizable, we recruited participants from the general population instead of university students.

\subsection{Participants and Procedure}

Participants and design: A total of 170 participants from the panel of an online research company $\left(44.1 \%\right.$ female; $\left(M_{\text {age }}=37.16\right.$ years, $S D=7.35$ years $\left.)\right)$ in Korea were randomly assigned to read one of four scenarios created with a 2 (primary color: red vs. blue) $\times 2$ (message framing: loss vs. gain) between-subjects design. Participants participated voluntarily for a monetary reward of $\$ 1.00$ for filled out the survey which required less than $3 \mathrm{~min}$ to complete.

Procedures: All participants were presented with a print advertisement regarding organ donation. We adapted an existing advertisement from an online campaign and modified it by manipulating the primary color and message framing. The message was printed in black letters, with the primary background color manipulated among subjects to be either red or blue. The manipulation of message frame either highlighted a gain-framed ("Save nine lives with one organ donor") or a loss-framed ("Stop nine deaths with one organ donor") message. Once participants had reviewed the offered materials, they rated their behavioral intention to become an organ donor as a result of seeing the campaign $(1=$ strongly disagree, $7=$ strongly agree; Cronbach's $\alpha=0.946)$. In addition, participants answered questions about their perception of self-efficacy toward organ donation $(1=$ strongly disagree, $7=$ strongly agree; Cronbach's $\alpha=0.948$ ) (see Appendix A). Finally, participants completed demographic measures and a suspicion probe. Participants were not aware of the experimental research questions in this study.

\subsection{Results}

Self-efficacy: To analyze the match effect between message framing and primary color on self-efficacy toward organ donation, a two-way analysis of variance (ANOVA) was performed. There was no significant main effect of framing and color $(p>0.10)$. However, more importantly, the results revealed a significant interaction effect between message framing and primary color of advertising $(F(1,166)=7.48, p=0.007)$. Specifically, the results of the contrast analysis revealed that when the primary color was red, participants perceived higher self-efficacy toward the organ donation message with loss framing $(M=4.53, S D=1.34)$ than with gain framing $(M=3.48, S D=1.43)$, $(F(1,166)=11.53, p<0.001)$. Conversely, when the primary color was blue, perceived self-efficacy did not differ across framing conditions $\left(M_{\text {loss framing }}=4.08, S D=1.56\right.$ vs. $M_{\text {gain framing }}=4.23, S D=1.41$; $F(1,166)=0.24, p>0.10$ ). Thus, H4a was supported, but H4b was not supported (see Figure 1). 


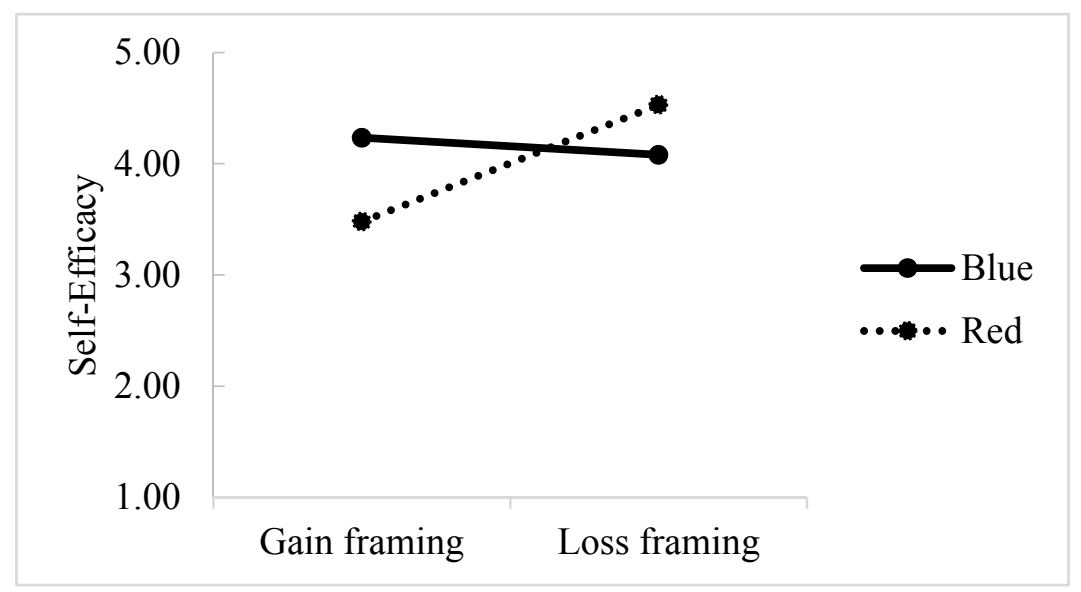

Figure 1. Self-efficacy as a function of primary color and message framing.

Behavioral intention: We conducted a two-way analysis of variance (ANOVA) to analyze the match effect between message framing and primary color on behavioral intention toward organ donation. There was no significant main effect of framing and color $(p>0.10)$. Consistent with previous results, there was a significant interaction effect between message framing and the primary color of advertising $(F(1,166)=4.692, p=0.032)$. More concretely, the results of the contrast analysis revealed that when the primary color was red, participants exhibit greater behavioral intention to become organ donors when the message is loss-framed $(M=4.04, S D=1.35)$ than when it was gain-framed $(M=3.49, S D=1.43),(F(1,166)=3.56, p=0.06)$. Conversely, when the primary color was blue, behavioral intention did not differ across framing conditions $\left(M_{\text {loss framing }}=3.91, S D=1.24 \mathrm{vs}\right.$. $\left.M_{\text {gain framing }}=4.23, S D=1.33 ; F(1,166)=1.39, p=0.239\right)$. Thus, H5a was supported, but H5b was not supported (see Figure 2).

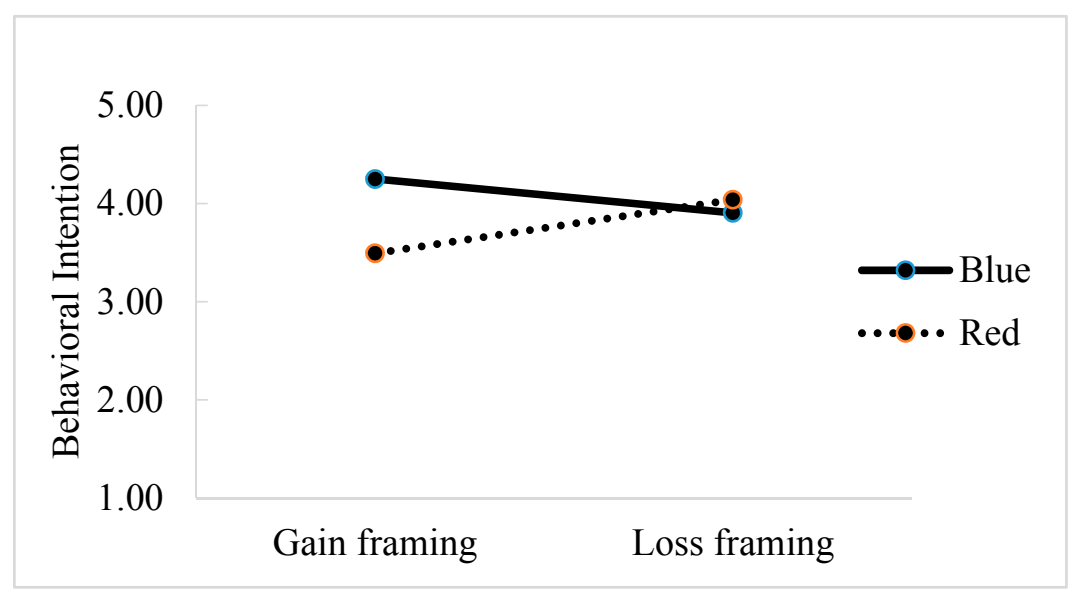

Figure 2. Behavioral intention as a function of primary color and message framing.

Self-efficacy as a mediator: We expected that the interaction of primary color by message framing on behavioral intention would be mediated by self-efficacy. To test H6, a bootstrapped mediated moderation analysis was performed (model 8; [50]). The mediation effect of self-efficacy (indirect effect $=0.152,95 \% \mathrm{CI}=(0.026,0.379))$ was significant, whereas the direct effect of interaction between the primary color and message framing on behavioral intention was not significant $(\beta=0.15, t=1.44, p=0.150)$. Therefore, the observed effect was completely mediated by self-efficacy [51]. Thus, H6 was supported (see Table A4 in Appendix B). 


\section{Discussion}

The current research examined the influence of processing fluency on intention to engage in a pro-social behavior. The results from Study 1 (pro-environmental campaign ad) and Study 2 (organ donation promotion ad) confirmed that those who perceived easiness in processing the information presented by a pro-social campaign ad are more likely to perceive themselves to have stronger capabilities to perform the desired actions. Such a high level of confidence or self-efficacy leads to a higher level of behavioral intention for them to participate in the advertised pro-social behavior. In addition, the results revealed that a match between color and message framing could influence the self-efficacy judgment for pro-social ads. Specifically, we expected blue-gain (positive) framing and red-loss (negative) framing would fit better than other pairs of the color-framing match (blue-loss or red-gain). While we observed a significant interaction effect in the expected direction, the difference driven by the message framing match was weak in the blue-color condition. This weaker effect can potentially be attributed to the association between the color blue and general pro-social behaviors. Despite the differences in framing, people may have perceived a certain level of fit between blue color and the contents of an ad for any pro-social campaigns.

Theoretically, this study contributes to the existing literature in several ways. First, the current findings add supporting evidence for the notion that the decisions involved in pro-social behavior are not limited to a conscious, deliberative, and cognitive process that considers moral obligations or rationally evaluates the benefits [3] as has long been believed. People use situationally construed feelings as information to form their judgment and decisions. Moreover, we demonstrated that an individual's donation intention is influenced by message framing and background colors. By showing the effect of contextual change without changing the contents of the advertising, our research supports the growing stream of research that focuses on the importance of peripheral elements and their influence on social marketing.

Second, emerging literature in the pro-social domain argues perceived control as the key construct that influences pro-social behaviors. Even for individuals with a strong sense of moral responsibility that meets with social norms, their behavioral intentions can be moderated by the perceived control over their actions and outcome. Extending this line of research, the current work highlights the importance of self-efficacy in leading to participation in pro-social behaviors. Specifically, we suggest processing fluency as a source of self-efficacy. Some studies have examined the effectiveness of processing fluency in prosocial domains (e.g., blood donation), but only a few attempted to investigate how it influences perceived control over the behavior. In particular, one prior study showed how the fit between individuals' mindset and message framing influenced recycling behavior and showed that self-efficacy mediated the effect [42]. Conceptually replicating their work, we showed how easiness in information processing enhances one's self-expectation and confidence about one's capacity. Further, our studies add to the generalizability of this framework by both demonstrating its general effect for pro-environmental issues in a natural setting (Study 1) and the specific condition in which color and framing matches in an organ donation advertisement (Study 2). An additional theoretical issue that arises in the current research is whether processing fluency is a meaningful predictor of pro-social behavior. Our results suggest that two alternative sources can facilitate pro-social behavior; that is, processing fluency and involvement toward a pro-social campaign are competing predictors. These results provide insightful evidence that both processing fluency and involvement could independently enhance engagement with prosocial campaigns, which means that processing fluency proposed by our theorem is a meaningful and valid explanation for engaging in pro-social behavior in the natural setting.

Our study provides a contribution to social marketing practice by identifying practical strategies to enhance consumers' behavioral intention to engage in social campaigns. First, the current study accentuates the importance of processing easiness of the contents of pro-social communication, especially when the decision involves a significant amount of effort or risk, which requires self-confidence about one's ability to perform the actions. While we demonstrated the effect of 
the framing-color match on the intention to engage in prosocial behavior in our study, various techniques to enhance processing fluency should be considered when developing pro-social campaign advertising. Obviously, pro-social campaign organizers should ensure a conceptual match between contents, framing, and other visual cues beyond framing-color fit. In addition, the use of familiar pictures and words, easy-to-read font or asymmetric design may be an effective way to improve processing easiness. Moreover, colors are ubiquitous but have been actively considered as a peripheral factor to create a particular image in pro-social domains (e.g., green for environmental issues and red for blood donation). Our study showed that appropriate use of color may facilitate actions when properly matched with framing. Specifically, social marketing practitioners may use red as a dominant color if they present the message describing potential loss. On the other hand, if the message illustrates potential gain, using blue as a dominant color is likely to be more effective.

Finally, the current study is not without limitations. First of all, given that we believe self-efficacy is an important variable to bridge the gap between attitude and behavior, actual field tests to replicate our hypothesis in a real-world context is a must to solidify our proposition. Moreover, while we focused on the positive aspect of processing fluency, recent studies suggest that disfluency may play a beneficial role in drawing attention and evoking interest [63]. For instance, disfluent presentation may be more effective when promoting simple and less-effortful pro-social acts such as donating a small amount of money for charity. Thus, further study is needed to identify moderators for the effect of fluency.

Author Contributions: H.K. suggested the initial research idea and performed the literature review. J.J. designed and executed the experiment, analyzed the data, and will be the primary party to handle the review process. Both authors elaborated on the research idea, developed the research model and hypotheses, and prepared the manuscript. In addition, both authors read and approved the final manuscript.

Funding: This research received no external funding.

Conflicts of Interest: The authors declare no conflict of interest.

\section{Appendix A. Details of the Study Instruments}

Table A1. Survey questionnaire: Study 1.

\begin{tabular}{l} 
Behavioral intentions \\
\hline How likely are you to engage the campaign in the advertising? $(1=$ highly unlikely, and $7=$ highly likely $)$ \\
How inclined are you to engage the campaign in the advertising? $(1=$ not very inclined, and $7=$ very inclined $)$ \\
How willing are you to provide personal information on their website and engage the campaign in the advertising? \\
$(1=$ very unwilling, and $7=$ very willing) \\
How likely are you to recommend participation in the campaign in the advertising to others? $(1=$ highly unlikely, and \\
$7=$ highly likely) \\
\hline Perceived efficacy \\
\hline I feel that through this environmental protection campaign I can make a difference \\
I feel that I know how to go about an environmental protection campaign \\
I believe that I know what steps I will take to engage in this environmental protection campaign \\
\hline Processing fluency \\
\hline It was difficult to process the information \\
It was easy to understand \\
It was difficult to comprehend \\
It was easy to process the information \\
\hline Involvement as Control Variable \\
\hline Participating in the pro-environmental program is valuable to me $(1=$ worthless, and $7=$ valuable) \\
Reducing the use of the disposable material is relevant to me $(1=$ irrelevant, and $7=$ relevant $)$ \\
Reducing the use of the disposable material is a concern to me $(1=$ of no concern to me, and $7=$ of concern to me $)$ \\
Reducing waste is important to me $(1=$ unimportant, and $7=$ important $)$ \\
\hline Demographics \\
\hline Age \\
Sex (male, female) \\
\hline For perceived efficacy, processing fluency, and involvement, answers were based on a seven-point Likert scale \\
where $1=$ strongly disagree, and $7=$ strongly agree.
\end{tabular}


Table A2. Experimental instrument: Study 2.

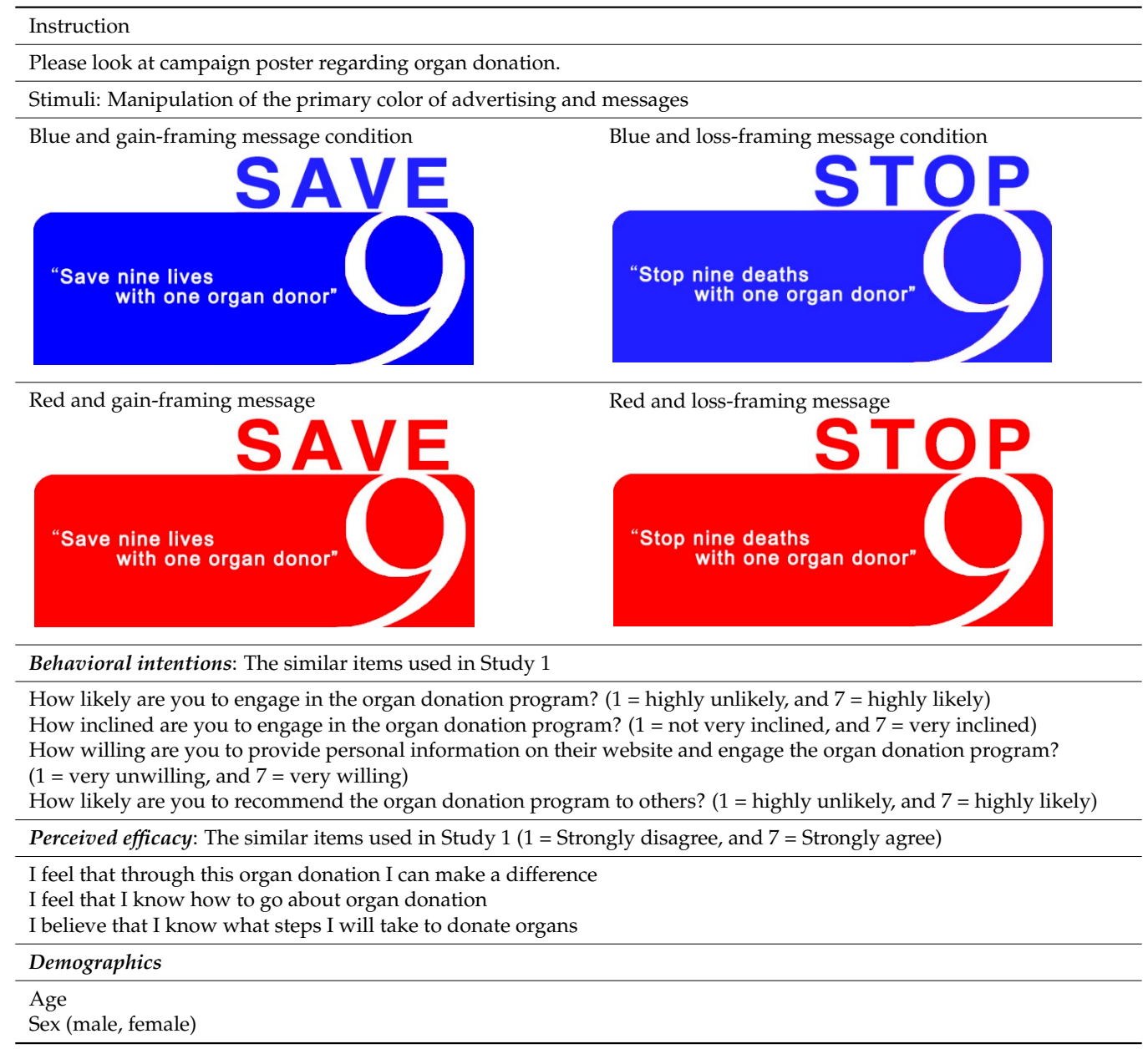

\section{Appendix B. Summary of Study Results}

Table A3. Results of Hypothesis testing: Study 1.

\begin{tabular}{ll}
\hline Hypothesis & Results \\
\hline H1. Self-efficacy has a positive effect on behavioral intention toward pro-social behavior & Supported \\
H2. Fluency has a positive effect on perceived self-efficacy toward the pro-social behavior & Supported \\
H3. Self-efficacy mediates the influence of fluency on behavioral intention toward the pro-social campaign & Supported \\
\hline
\end{tabular}

Table A4. Results of Hypothesis testing: Study 2.

\begin{tabular}{ll}
\hline Hypothesis & Results \\
\hline $\begin{array}{l}\text { H4. Color will moderate the relationship between message framing and self-efficacy } \\
\text { toward an organ donation campaign. }\end{array}$ & Partially Supported \\
\hline $\begin{array}{l}\text { H4a. Consumers will show greater self-efficacy with the loss framing condition than with } \\
\text { the gain framing when the primary color of advertising is red. }\end{array}$ & Supported \\
\hline $\begin{array}{l}\text { H4b. Consumers will show greater self-efficacy with the gain framing condition than with } \\
\text { the loss framing when the primary color of advertising is blue. }\end{array}$ & Not Supported \\
\hline $\begin{array}{l}\text { H5. Color will moderate the relationship between message framing and behavioral } \\
\text { intention to join an organ donation campaign. }\end{array}$ & Partially Supported \\
\hline $\begin{array}{l}\text { H5a. Consumers will show greater behavioral intention with the loss framing condition } \\
\text { than with the gain framing when the primary color of advertising is red. }\end{array}$ & Supported \\
\hline $\begin{array}{l}\text { H5b. Consumers will show greater behavioral intention with the gain framing condition } \\
\text { than with the loss framing when the primary color of advertising is blue. }\end{array}$ & Not Supported \\
\hline $\begin{array}{l}\text { H6. Self-efficacy mediates the effects of the two-way interaction between primary color } \\
\text { and framing on behavioral intention toward the pro-social campaign }\end{array}$ & Supported \\
\hline
\end{tabular}




\section{References}

1. Rice, R.E.; Atkin, C.K. (Eds.) Public Communication Campaigns; Sage: Newcastle upon Tyne, UK, 2012.

2. Geyer, R.; Jambeck, J.R.; Law, K.L. Production, use, and fate of all plastics ever made. Sci. Adv. 2017, 3, e1700782. [CrossRef] [PubMed]

3. Bamberg, S.; Moser, G. Twenty years after Hines, Hungerford, and Tomera: A new meta-analysis of psycho-social determinants of pro-environmental behaviour. J. Environ. Psychol. 2007, 27, 14-25. [CrossRef]

4. Hall, C.M.; Le-Klähn, D.-T.; Ram, Y. Tourism, Public Transport and Sustainable Mobility; Channel View: Bristol, UK, 2017.

5. Venhoeven, L.A.; Bolderdijk, J.W.; Steg, L. Explaining the Paradox: How Pro-Environmental Behaviour can both Thwart and Foster Well-Being. Sustainability 2013, 5, 1372-1386. [CrossRef]

6. Ajzen, I. From intentions to actions: A theory of planned behavior. In Action Control; Springer: Berlin, Germany, 1985; pp. 11-39.

7. Locke, E.A.; Latham, G.P. Building a practically useful theory of goal setting and task motivation. A 35-year odyssey. Am. Psychol. 2002, 57, 705-717. [CrossRef] [PubMed]

8. Bandura, A. Self-efficacy: Toward a unifying theory of behavioral change. Psychol. Rev. 1977, 84, $191-215$. [CrossRef] [PubMed]

9. Bandura, A. Human agency in social cognitive theory. Am. Psychol. 1989, 44, 1175-1184. [CrossRef] [PubMed]

10. Pajares, F.; Urdan, T. Self-Efficacy Beliefs of Adolescents; IAP-Information Age Pub. Inc.: Greenwich, CT, USA, 2006.

11. Bandura, A. The primacy of self-regulation in health promotion. Appl. Psychol. 2005, 54, 245-254. [CrossRef]

12. Feltz, D.L.; Short, S.E.; Sullivan, P.J. Self-Efficacy in Sport; Human Kinetics: Champaign, IL, USA, 2008.

13. Combs, G.M.; Luthans, F. Diversity training: Analysis of the impact of self-efficacy. Hum. Resour. Dev. Q. 2007, 18, 91-120. [CrossRef]

14. Schwarz, N. Metacognitive experiences in consumer judgment and decision making. J. Consum. Psychol. 2004, 14, 332-348. [CrossRef]

15. Tapia-Fonllem, C.; Corral-Verdugo, V.; Fraijo-Sing, B.; Durón-Ramos, M.F. Assessing sustainable behavior and its correlates: A measure of pro-ecological, frugal, altruistic and equitable actions. Sustainability 2013, 5, 711-723. [CrossRef]

16. Bandura, A. Self-Efficacy in Changing Societies; Cambridge University Press: Cambridge, UK, 1995.

17. Kanfer, R.; Ackerman, P.L. A self-regulatory skills perspective to reducing cognitive interference. In Cognitive Interference: Theories, Methods, and Findings; Sarason, I.G., Pierce, G.R., Pierce, B.R., Eds.; Erlbaum: Mahwah, NJ, USA, 1996; pp. 153-171.

18. De Young, R. New ways to promote pro-environmental behavior: Expanding and evaluating motives for environmentally responsible behavior. J. Soc. Issues 2000, 56, 509-526. [CrossRef]

19. Newcomb, M.D.; Harlow, L.L. Life events and substance use among adolescents: Mediating effects of perceived loss of control and meaninglessness in life. J. Pers. Soc. Psychol. 1986, 51, 564-577. [CrossRef]

20. DiClemente, C.C. Self-efficacy and smoking cessation maintenance: A preliminary report. Cogn. Ther. 1981, 5, 175-187. [CrossRef]

21. Tabernero, C.; Hernandez, B. Self-Efficacy and Intrinsic Motivation Guiding Environmental Behavior. Environ. Behav. 2011, 43, 658-675. [CrossRef]

22. Tang, Z.J.; Chen, X.H.; Luo, J.H. Determining Socio-Psychological Drivers for Rural Household Recycling Behavior in Developing Countries: A Case Study From Wugan, Hunan, China. Environ. Behav. 2011, 43, 848-877. [CrossRef]

23. Thøgersen, J.; Grønhøj, A. Electricity saving in households-A social cognitive approach. Energy Policy 2010, 38, 7732-7743. [CrossRef]

24. Lubell, M. Environmental activism as collective action. Environ. Behav. 2002, 34, 431-454. [CrossRef]

25. Basil, D.Z.; Ridgway, N.M.; Basil, M.D. Guilt and giving: A process model of empathy and efficacy. Psychol. Mark. 2008, 25, 1-23. [CrossRef]

26. Giles, M.; McClenahan, C.; Cairns, E.; Mallet, J. An application of the Theory of Planned Behaviour to blood donation: The importance of self-efficacy. Health Educ. Res. 2004, 19, 380-391. [CrossRef] 
27. Clowes, R.; Masser, B.M. Right here, right now: The impact of the blood donation context on anxiety, attitudes, subjective norms, self-efficacy, and intention to donate blood. Transfusion 2012, 52, 1560-1565. [CrossRef] [PubMed]

28. Brug, J.; Vugt, M.V.; van Den Borne, B.; Brouwers, A.; Hooff, H.V. Predictors of willingness to register as an organ donor among Dutch adolescents. Psychol. Health 2000, 15, 357-368. [CrossRef]

29. Hyde, M.K.; White, K.M. To be a donor or not to be? Applying an extended theory of planned behavior to predict posthumous organ donation intentions. J. Appl. Soc. Psychol. 2009, 39, 880-900. [CrossRef]

30. Reubsaet, A.; Brug, J.; De Vet, E.; Van Den Borne, B. The effects of practicing registration of organ donation preference on self-efficacy and registration intention: An enactive mastery experience. Psychol. Health 2003, 18, 585-594. [CrossRef]

31. McCarty, J.A.; Shrum, L. The influence of individualism, collectivism, and locus of control on environmental beliefs and behavior. J. Public Policy Mark. 2001, 20, 93-104. [CrossRef]

32. Park, K.; Ryu, G. The Effect of Regulatory Focus on Individuals' Donation Behavior. Sustainability 2018, 10, 760. [CrossRef]

33. Lee, A.Y.; Labroo, A. Effects of conceptual and perceptual fluency on affective judgment. J. Mark. Res. 2004, 41, 151-165. [CrossRef]

34. Reber, R.; Schwarz, N.; Winkielman, P. Processing fluency and aesthetic pleasure: Is beauty in the perceiver's processing experience? Pers. Soc. Psychol. Rev. 2004, 8, 364-382. [CrossRef]

35. Whittlesea, B.W. Illusions of familiarity. J. Exp. Psychol. Learn. Mem. Cogn. 1993, 19, 1235-1253. [CrossRef]

36. Winkielman, P.; Schwarz, N.; Fazendeiro, T.; Reber, R. The hedonic marking of processing fluency: Implications for evaluative judgment. In The Psychology of Evaluation: Affective Processes in Cognition and Emotion; Musch, J., Klauer, K.C., Eds.; Lawrence Erlbaum: Mahwah, NJ, USA, 2003; pp. 189-217.

37. Fazendeiro, T.; Winkielman, P.; Luo, C.; Lorah, C. False recognition across meaning, language, and stimulus format: Conceptual relatedness and the feeling of familiarity. Mem. Cogn. 2005, 33, 249-260. [CrossRef]

38. Alter, A.L.; Oppenheimer, D.M. Uniting the tribes of fluency to form a metacognitive nation. Pers. Soc. Psychol. Rev. 2009, 13, 219-235. [CrossRef]

39. Pandelaere, M.; Millet, K.; Van den Bergh, B. Madonna or Don McLean? The effect of order of exposure on relative liking. J. Consum. Psychol. 2010, 20, 442-451. [CrossRef]

40. Reber, R.; Winkielman, P.; Schwarz, N. Effects of perceptual fluency on affective judgments. Psychol. Sci. 1998, 9, 45-48. [CrossRef]

41. Shah, A.K.; Oppenheimer, D.M. Easy does it: The role of fluency in cue weighting. Judgm. Decis. Mak. 2007, 2, 371-379.

42. White, K.; MacDonnell, R.; Dahl, D.W. It's the Mind-Set That Matters: The Role of Construal Level and Message Framing in Influencing Consumer Efficacy and Conservation Behaviors. J. Mark. Res. 2011, 48, 472-485. [CrossRef]

43. Rhodes, M.G.; Castel, A.D. Memory predictions are influenced by perceptual information: Evidence for metacognitive illusions. J. Exp. Psychol. Gen. 2008, 137, 615-625. [CrossRef]

44. Alter, A.L.; Oppenheimer, D.M.; Epley, N.; Eyre, R.N. Overcoming intuition: Metacognitive difficulty activates analytic reasoning. J. Exp. Psychol. Gen. 2007, 136, 569-576. [CrossRef] [PubMed]

45. Carpenter, S.K.; Olson, K.M. Are pictures good for learning new vocabulary in a foreign language? Only if you think they are not. J. Exp. Psychol. Learn. Mem. Cogn. 2012, 38, 92-101. [CrossRef] [PubMed]

46. White, K.; Peloza, J. Self-benefit versus other-benefit marketing appeals: Their effectiveness in generating charitable support. J. Mark. 2009, 73, 109-204. [CrossRef]

47. Chae, H.; Hoegg, J. The future looks "Right": Effects of the horizontal location of advertising images on product attitude. J. Consum. Res. 2013, 40, 223-238. [CrossRef]

48. Lee, A.Y.; Aaker, J.L. Bringing the frame into focus: The influence of regulatory fit on processing fluency and persuasion. J. Per. Soc. Psychol. 2004, 86, 205-218. [CrossRef]

49. Zaichkowsky, J.L. Measuring the involvement construct. J. Consum. Res. 1985, 12, 341-352. [CrossRef]

50. Hayes, A.F. PROCESS: A versatile computational tool for observed variable mediation, moderation, and conditional process modeling (White Paper). Available online: http://www.afhayes.com/public/ process2012.pdf (accessed on 21 August 2018).

51. Zhao, X.S.; Lynch, J.G.; Chen, Q.M. Reconsidering Baron and Kenny: Myths and Truths about Mediation Analysis. J. Consum. Res. 2010, 37, 197-206. [CrossRef] 
52. De Bock, T.; Pandelaere, M.; Van Kenhove, P. When colors backfire: The impact of color cues on moral judgment. J. Consum. Psychol. 2013, 23, 341-348. [CrossRef]

53. Seo, J.Y.; Scammon, D.L.J.M.L. Do green packages lead to misperceptions? The influence of package colors on consumers' perceptions of brands with environmental claims. Mark. Lett. 2017, 28, 357-369. [CrossRef]

54. Elliot, A.J.; Maier, M.A.; Binser, M.J.; Friedman, R.; Pekrun, R. The effect of red on avoidance behavior in achievement contexts. Pers. Soc. Psychol. Bull. 2009, 35, 365-375. [CrossRef] [PubMed]

55. Elliot, A.J.; Maier, M.A.; Moller, A.C.; Friedman, R.; Meinhardt, J. Color and psychological functioning: The effect of red on performance attainment. J. Exp. Psychol. Gen. 2007, 136, 154-168. [CrossRef] [PubMed]

56. Meyers-Levy, J.; Peracchio, L.A. Understanding the effects of color: How the correspondence between available and required resources affects attitudes. J. Consum. Res. 1995, 22, 121-138. [CrossRef]

57. Fraser, T.; Banks, A. Designer's Color Manual: The Complete Guide to Color Theory and Application; Chronicle Books: San Francisco, CA, USA, 2004.

58. Mehta, R.; Zhu, R.J. Blue or red? Exploring the effect of color on cognitive task performances. Science 2009, 323, 1226-1229. [CrossRef] [PubMed]

59. Tversky, A.; Kahneman, D. The framing of decisions and the psychology of choice. Science 1981, 211, $453-458$. [CrossRef]

60. Deng, X.; Kahn, B.E. Is your product on the right side? The "location effect" on perceived product heaviness and package evaluation. J. Mark. Res. 2009, 46, 725-738. [CrossRef]

61. Lee, A.Y.; Keller, P.A.; Sternthal, B. Value from regulatory construal fit: The persuasive impact of fit between consumer goals and message concreteness. J. Consum. Res. 2009, 36, 735-747. [CrossRef]

62. Maio, G.R.; Haddock, G. Attitude change. In Social Psychology: Handbook of Basic Principles; Kruglanski, A.W., Higgins, E.T., Eds.; Guilford Press: New York, NY, USA, 2007; pp. 565-586.

63. Labroo, A.A.; Pocheptsova, A. Metacognition and consumer judgment: Fluency is pleasant but disfluency ignites interest. Curr. Opin. Psychol. 2016, 10, 154-159. [CrossRef]

(C) 2018 by the authors. Licensee MDPI, Basel, Switzerland. This article is an open access article distributed under the terms and conditions of the Creative Commons Attribution (CC BY) license (http:/ / creativecommons.org/licenses/by/4.0/). 